\section{Victim of violent death: what is the role of alcoholemia?}

\author{
Ivan Dieb Miziara ${ }^{1 *}$ and Carmen Silvia Molleis Galego Miziara² \\ ${ }^{1}$ Head of the Department of Legal Medicine, Ethics and Social Medicine of the Faculty of Medicine \\ of São Paulo University, São Paulo, Brazil \\ ${ }^{2}$ Assistant Professor, Discipline of Legal Medicine and Bioethics, ABC School of Medicine, São \\ Paulo, Brazil
}

\section{Abstract}

Introduction: The tendency to impulsive behaviors and/or violence is exacerbated after alcohol consumption. Still, the relation between alcohol/violent deaths reported in the literature is not accurate, and in general, alcohol is only seen as a trigger to aggressive actions. The relationship of the victims with their blood alcohol is less studied. They were especially concerned about the role of alcohol as a risk factor for victims of unnatural death. Thus, our goal is to check the influence of alcohol in victims of violent deaths as homicides, suicides, and accidents.

Materials and methods: Retrospectively the medical records of 805 autopsies performed at the Institute of Forensic Medicine (IML) of Franco da Rocha, in the period 2001 to 2017 were reviewed. The variables studied were sex, age, types of violent death rates, and alcohol - these were considered positive when above $0.3 \mathrm{mg} / \mathrm{ml}$.

The dosage of blood alcohol concentration (BAC) was performed using samples of $10 \mathrm{ml}$ of blood collected at necropsy, is preferably taken from the cardiac chambers or of the right femoral vein. Dosages of alcohol in blood samples were done in the Forensic Toxicology Center of the IML by gas chromatography, using the technique of separation "headspace" and double column.

Results: Drug testing for alcohol was available for $488(79.1 \%)$ of 617 necropsies. Of the 617 subjects studied, $532(85.7 \%)$ were male, and $85(13.8 \%)$ were females (with high rates of adolescents). The vast majority $(n=230)$ were killed, and $40.5 \%$ of victims had BAC above $0.3 \mathrm{mg} /$ $\mathrm{ml}$ of blood. Traffic accidents came next, accounting for 181 deaths, with $41 \%$ of victims presenting positive BAC.

Discussion: High blood alcohol levels of the victims were associated mainly with the genesis of accidents (drowning, falls, traffic, aspiration/ smothering) and murder (with impaired ability to resist or by causing the release of impulses to engage in violent situations), about $40 \%$ of cases.

Conclusion: Our results indicate that alcohol abuse is a risk factor for victims of violent death. In these cases, alcohol has two types of action. Direct: contributes to accidents of various kinds - from traffic by decreasing powers of concentration, attention, and loss of reflexes, to other types of accidents such as drowning, falls, swallowing disorders causing airway obstruction, and mechanical asphyxia. And they were indirect, making it easier for individuals to engage in conflict (and thus become victims of crimes).

\begin{abstract}
More Information
*Address for Correspondence: Ivan Dieb Miziara, M.D; Ph.D, Rua Teodoro Sampaio, 352-cj22, ZIP Code: 05406-000, São Paulo, Brazil, Tel: 55-11-991487678; Email: Ivanmiziara@gmail.com; Ivan.miziara@usp.br; miz@uol.com.br
\end{abstract}

Submitted: August 14, 2021
Approved: August 24, 2021
Published: August 25, 2021

How to cite this article: Miziara ID, Galego Miziara CSM. Victim of violent death: what is the role of alcoholemia? J Forensic Sci Res. 2021; 5: 048-052.

DOI: 10.29328/journal.jfsr.1001027

ORCiD: orcid.org/0000-0001-7180-8873

Copyright: @ 2021 Miziara ID, et al. This is an open access article distributed under the Creative Commons Attribution License, which permits unrestricted use, distribution, and reproduction in any medium, provided the original work is properly cited.

\section{Check for updates}

(8) open access

\section{Introduction}

Deaths due to external causes are a severe public health problem in Brazil - being the third leading cause of mortality in the country [1]. Furthermore, there is evidence that the tendency to impulsive and violent behavior is exacerbated after alcohol consumption. Still, the relationship between alcohol and violent deaths is described in the medical literature without much precision. For this reason, some authors believe that the role of "alcohol as a relevant factor in cases of sudden or unexpected or unnatural death seems to be underestimated" [2].

However, some studies demonstrate that the relationship between blood alcohol and fatal victims (specifical drivers) of traffic accidents reaches $35 \%$ and up to $48.6 \%$ (in the latter case, without specifying whether the victim is a driver or a passenger) [3,4]. Likewise, other studies show that in violent 
cases with victims, about a third of the aggressors (32.6\%) were drunk at the time of the aggression [5]. However, not many studies in the medical literature make this correlation with other types of violent death, highlighting (or excluding) alcohol consumption as a factor that increases the risk of the victim suffering a violent death [6]. Or that is: the role of alcohol abuse by victims of violent death is poorly studied in detail. It is also worth remembering that the relationship between alcohol consumption and violence appears in several population studies, especially among those who perpetrate some aggression against others. In Brazil, a survey that included 108 Brazilian cities with a high population density ( $>200$ thousand inhabitants) showed that in family violence cases, about $17 \%$ of the aggressors were under the effects of alcohol [7]. In Latin America, in a study involving eight cities (Salvador and Rio de Janeiro, Brazil; Santiago, Chile; Cali, Colombia; San José, Costa Rica; San Salvador, El Salvador; Caracas, Venezuela), $68 \%$ of the attackers had consumed alcohol before assaulting their partners [8]. Other types of violence also seem to be related to high alcohol consumption, such as cases of rape. A study carried out in Northern Ireland by Hall, et al., Demonstrated that in cases of sexual violence, the aggressors had consumed alcohol and other drugs in about $78 \%$ of the occurrences [9].

The problem becomes even more serious when individuals of younger age groups are also affected. Abramovay and Castro carried out a study demonstrating the advancement of alcohol use among Brazilian adolescents, outlining their sociodemographic profile and verifying that drinking has already started since elementary school [10].

Heninger and Hanzlick, studying unnatural causes of death among children and adolescents in the United States, concluded that, in cases of accidental death not due to traffic accidents, the vast majority of victims had high blood alcohol levels [11].

It is also important to emphasize that alcohol consumption in Brazil is characteristically high. A national household survey with a population from 12 to 65 years old estimated a prevalence of $74.6 \%$ of alcohol use (socially) and $12.3 \%$ of alcohol dependence in the studied population [12].

In 632 cases of suicide in the city of São Paulo in 2005, Ponce et al. concluded that $33.1 \%$ of the victims had positive blood alcohol levels with a higher prevalence for males (37.1\% against $20.1 \%$ ). That is, they concluded that one-third of the sample's suicides were committed shortly after alcohol consumption [13].

In a study published in 2018 (in which we participated), in the city of São Paulo, alcohol was the main substance consumed before the fatal event [14].

However, as we have already said, the correlation between alcohol use and abuse and violent deaths is still poorly studied in our country, when it comes to fatal victims. Thus, the objective of this study is to analyze the relationship between victims' blood alcohol levels and violent deaths, in the microregion formed by some municipalities in Greater São Paulo (Franco da Rocha, Caieiras, Mairiporã and Francisco Morato), which are served by the Medical Expertise Team Franco da Rocha of the Legal Medical Institute of the State of São Paulo. These municipalities are characterized as suburbs of the city - and serve only as a "dormitory" for a population that works in São Paulo.

It is also important to note that, in Brazil, under the law, all cases of death of non-natural origin, that is: violent deaths, and those cases in which violence is suspected, must be submitted to necroscopic examination at the Medical Legal Institute, to verify the exact nature of death.

\section{Methods}

The Ethics Committee approved the present study for Analysis of Research Projects - CAPPesq - of the Faculty of Medicine of the University of São Paulo, under number 0090/09, on 03/11/2009 and by the Scientific Committee of the Medical Legal Institute of the State of São Paulo with the condition that it will be public after five (5) years of the last data collected (due Brazilian Law requirements).

Retrospectively, the data from the medical records of 805 autopsies performed at the Medical Legal Institute (IML) in Franco da Rocha, from 2001 to 2017, were reviewed.

One hundred sixty (160) cases were excluded from the analysis whose autopsy showed death from natural causes. Another 20 cases were also excluded because the corpses are putrefied (although some authors consider that the possibility of false-positive results is not relevant) 15 or carbonized corpses, which did not have conditions to collect the exam.

Another seven cases, because they are premature newborns and one because they are exhumated, were also excluded from the sample.

The data obtained were analyzed statistically using the SPS program. We used the Q Square Test for the statistical comparison between sex (male $\mathrm{x}$ female).

The variables studied were sex, age, types of violent death, and blood alcohol levels, which were considered positive when above $0.3 \mathrm{mg} / \mathrm{dL}$ (the limit that Brazilian law imposes on drivers when driving a vehicle).

The blood-alcohol level measurement was performed using $10 \mathrm{ml}$ blood samples collected during autopsies, preferably from cardiac chambers (left ventricle).

The alcoholic dosages in the blood samples were performed in the Nucleus of Forensic Toxicology of the IML by gas chromatography, using separation by "headspace" and double column. 


\section{Results}

The demographic characteristics of the studied group can be seen in Table 1. The legal nature of the deaths (i.e., homicide, suicide, accident) is presented in Table 2. Finally, the prevalence and median blood alcohol levels for the groups, according to the natural cause of death, are shown in Table 3.

Of the 617 individuals analyzed, 532 (85.7\%) were male and 85 (13.8\%) female. The individuals were divided into groups of different age groups. The distribution of age groups, according to sex, is shown in Table 1.
The average age for males was 30 years old (21-43) and for females, 26 years old. The prevalences of the different causes of death according to their legal nature are shown in Table 2. The vast majority ( $n=230$ ) was due to homicide, and in these cases, $40.5 \%$ of the victims had blood alcohol levels above $0.3 \mathrm{dg} / \mathrm{L}$ of blood. Traffic accidents followed, accounting for 181 deaths, with $41 \%$ of victims having positive blood alcohol levels.

\section{Discussion}

The present study confirms some findings from other

Table 1: Age of 617 individuals whose autopsy showed death due to violent causes according to sex (2001-2017).

\begin{tabular}{|c|c|c|c|c|}
\hline & \multicolumn{2}{|c|}{$\operatorname{Sex}$} & \multirow[b]{2}{*}{$p=0,02$} & \multirow[b]{2}{*}{ Total $(n=617)$} \\
\hline & Male $(n=532)$ & Female $(n=85)$ & & \\
\hline Age (years) & $30(21-43)$ & $26(17-49)$ & & $30(21-44)$ \\
\hline 0 a 4 & $15(2,8 \%)$ & $6(7,1 \%)$ & & $21(3,4 \%)$ \\
\hline 5 a 11 & $7(1,3 \%)$ & $5(5,9 \%)$ & & $12(1,9 \%)$ \\
\hline 12 a 17 & $48(9,0 \%)$ & $11(12,9 \%)$ & & $59(9,6 \%)$ \\
\hline 18 a 23 & $99(18,6 \%)$ & $11(12,9 \%)$ & & $110(17,8 \%)$ \\
\hline 24 a 29 & $94(17,7 \%)$ & $12(12,9 \%)$ & & $105(17,0 \%)$ \\
\hline 30 a 39 & $95(17,9 \%)$ & $12(14,1 \%)$ & & $107(17,3 \%)$ \\
\hline 40 a 49 & $92(17,3 \%)$ & $9(10,6 \%)$ & & $101(16,4 \%)$ \\
\hline 50 a 59 & $47(8,6 \%)$ & $10(11,8 \%)$ & & $57(9,2 \%)$ \\
\hline 60 ou mais & $35(6,6 \%)$ & $10(11,8 \%)$ & & $45(7,3 \%)$ \\
\hline
\end{tabular}

Table 2: Legal nature of causes of death (2001-2007).

\begin{tabular}{|c|c|c|c|}
\hline Cause & $\mathbf{N}$ & $\%$ group & $\%$ Total \\
\hline $\begin{array}{l}\text { Homicide } \\
\text { Firearm } \\
\text { Sharp force trauma } \\
\text { Blunt Agent } \\
\text { Asphyxiation } \\
\text { Incised wounds on the neck } \\
\text { Drowning } \\
\text { Total }\end{array}$ & $\begin{array}{c}162 \\
30 \\
30 \\
5 \\
2 \\
1 \\
230\end{array}$ & $\begin{array}{c}70,4 \% \\
13,0 \% \\
13,0 \% \\
2,2 \% \\
0,9 \% \\
0,4 \% \\
100,0 \%\end{array}$ & $\begin{array}{c}26,3 \% \\
4,9 \% \\
4,9 \% \\
0,8 \% \\
0,3 \% \\
0,2 \% \\
37,3 \%\end{array}$ \\
\hline $\begin{array}{c}\text { Traffic Accident } \\
\text { Run Over } \\
\text { Vehicle } \\
\text { Train } \\
\text { Driver } \\
\text { Car } \\
\text { Motorcycle } \\
\text { Byke } \\
\text { Passenger } \\
\text { Car } \\
\text { Motorcycle } \\
\text { Total }\end{array}$ & $\begin{array}{c}67 \\
46 \\
21 \\
84 \\
46 \\
31 \\
7 \\
30 \\
28 \\
2 \\
181\end{array}$ & $\begin{array}{c}37,0 \% \\
25,4 \% \\
11,6 \% \\
46,4 \% \\
25,4 \% \\
17,1 \% \\
6,1 \% \\
16,6 \% \\
15,5 \% \\
1,1 \% \\
100,0 \%\end{array}$ & $\begin{array}{c}10,9 \% \\
7,5 \% \\
3,4 \% \\
13,6 \% \\
7,5 \% \\
5,0 \% \\
1,1 \% \\
4,9 \% \\
4,6 \% \\
0,3 \% \\
29,3 \%\end{array}$ \\
\hline Drowning & 69 & $100,0 \%$ & $11,2 \%$ \\
\hline Fall & 56 & $100,0 \%$ & $9,1 \%$ \\
\hline $\begin{array}{l}\text { Suicide } \\
\text { Hanging } \\
\text { Intoxication } \\
\text { Firearm } \\
\text { Sharp trauma } \\
\text { Others* } \\
\text { Total }\end{array}$ & $\begin{array}{c}20 \\
9 \\
7 \\
2 \\
3 \\
41\end{array}$ & $\begin{array}{c}48,8 \% \\
22,0 \% \\
17,1 \% \\
4,9 \% \\
7,2 \% \\
100,0 \%\end{array}$ & $\begin{array}{c}3,2 \% \\
1,5 \% \\
1,1 \% \\
0,3 \\
0,5 \% \\
6,6 \%\end{array}$ \\
\hline Asphyxiation & 15 & $100,0 \%$ & $2,4 \%$ \\
\hline Intoxication & 9 & $100,0 \%$ & $1,5 \%$ \\
\hline Others Accidents ** & 5 & $100,0 \%$ & $0,8 \%$ \\
\hline Fire/carbonization & 4 & $100,0 \%$ & $0,6 \%$ \\
\hline Burial asphyxiation & 3 & $100,0 \%$ & $0,5 \%$ \\
\hline Infanticide & 2 & $100,0 \%$ & $0,3 \%$ \\
\hline Infected Abortion & 1 & $100,0 \%$ & $0,2 \%$ \\
\hline Work Accident & 1 & $100,0 \%$ & $0,2 \%$ \\
\hline
\end{tabular}




\begin{tabular}{|c|c|c|c|}
\hline Cause & $\begin{array}{c}\mathbf{N}(\%) \\
\text { Available cases }\end{array}$ & $\begin{array}{l}\text { Positive blood alcohol } \\
\text { (>0.3 } \mathrm{mg} / \mathrm{ml}) \text { in } \%\end{array}$ & $\begin{array}{l}\text { Blood alcohol level (mg/ml) } \\
\text { (in positive cases) }\end{array}$ \\
\hline $\begin{array}{l}\text { Homicide } \\
\text { Firearm } \\
\text { Sharp force trauma } \\
\text { Blunt force trauma } \\
\text { Asphyxiation } \\
\text { Incised wounds on the neck } \\
\text { Drowning } \\
\text { Total }\end{array}$ & $\begin{array}{c}149(92,0 \%) \\
24(80,0 \%) \\
25(83,3 \%) \\
5(100,0 \%) \\
1(50,0 \%) \\
1(100,0 \%) \\
205(89,1 \%)\end{array}$ & $\begin{array}{l}57(38,3 \%) \\
8(33,3 \%) \\
14(56,0 \%) \\
2(40,0 \%) \\
1(100,0 \%) \\
1(100,0 \%) \\
83(40,5 \%)\end{array}$ & $\begin{array}{c}1,3(0,8-1,8) \\
1,6(1,4-2,4) \\
1,8(0,6-3,4) \\
0,5-0,5 \\
2,3 \\
3,4 \\
1,4(0,8-2,2)\end{array}$ \\
\hline \begin{tabular}{|c} 
Traffic accidents \\
Run over \\
Vehicle \\
Train \\
Driver \\
Car \\
Motorcycle \\
Bike \\
Passenger \\
Car \\
Motorcycle \\
Total
\end{tabular} & $\begin{array}{c}53(79,1 \%) \\
33(71,7 \%) \\
20(95,2 \%) \\
71(84,5 \%) \\
39(84,8 \%) \\
27(87,1 \%) \\
5(71,4 \%) \\
20(66,7 \%) \\
18(64,3 \%) \\
2(100,0 \%) \\
144(79,6 \%)\end{array}$ & $\begin{array}{c}25(47,2 \%) \\
16(48,5 \%) \\
9(45,0 \%) \\
29(40,8 \%) \\
19(48,7 \%) \\
8(29,6 \%) \\
1(20,0 \%) \\
5(25,0 \%) \\
5(27,8 \%) \\
0(0,0 \%) \\
59(41,0 \%)\end{array}$ & $\begin{array}{c}1,9(1,0-3,0) \\
2,4(1,4-3,2) \\
0,9(0,7-2,1) \\
1,9(1,2-2,3) \\
1,9(1,2-2,4) \\
1,8(1,0-2,5) \\
1,6 \\
0,7(0,6-0,7) \\
0,7(0,6-0,7) \\
- \\
1,9(0,9-2,4)\end{array}$ \\
\hline Drowning & $64(92,8 \%)$ & $32(50,0 \%)$ & $1,2(0,7-1,9)$ \\
\hline Fall & $16(28,6 \%)$ & $8(50,0 \%)$ & $1,4(0,5-3,6)$ \\
\hline $\begin{array}{l}\text { Suicide } \\
\text { Hanging } \\
\text { Intoxication } \\
\text { Firearm } \\
\text { Sharp force trauma } \\
\text { Others* } \\
\text { Total }\end{array}$ & $\begin{array}{c}19(95,0 \%) \\
8(88,9 \%) \\
7(100,0 \%) \\
2(100,0 \%) \\
2(66,7 \%) \\
38(92,7 \%)\end{array}$ & $\begin{array}{c}7(36,8 \%) \\
0(0,0 \%) \\
1(14,3 \%) \\
1(50,0 \%) \\
0(0,0 \%) \\
9(23,7 \%)\end{array}$ & $\begin{array}{c}2,3(0,8-2,8) \\
- \\
1,5 \\
1,7 \\
- \\
2,2(1,2-2,7)\end{array}$ \\
\hline Aspiration & $4(26,7 \%)$ & $2(50,0 \%)$ & $4,1(3,4-4,8)$ \\
\hline Intoxication & $9(100,0 \%)$ & $6(66,7 \%)$ & $3,1(0,7-4,2)$ \\
\hline Others accidents ${ }^{* *}$ & $4(80,0 \%)$ & $0(0,0 \%)$ & - \\
\hline Fire/carbonization & $3(75,0 \%)$ & $0(0,0 \%)$ & - \\
\hline Burial asphyxiation & $1(33,3 \%)$ & $1(100,0 \%)$ & 1,1 \\
\hline Infanticide & $1(50,0 \%)$ & $0(0,0 \%)$ & - \\
\hline Infected abortion & $0(0,0 \%)$ & - & - \\
\hline Work accident & $1(100,0 \%)$ & $0(0,0 \%)$ & - \\
\hline
\end{tabular}

researchers on the topic in question (association between blood alcohol and deaths from unnatural causes) [2,3]. The first is concerning the sex of the individuals involved. In all age groups, there was a predominance of male individuals, with statistical significance.

In general, these are young adults (18 to 49 years of age). However, it is essential to highlight the high incidence of the problem among adolescents (aged 12 to 17 years), corresponding to $9.6 \%$ of the cases studied, corroborating the findings by Abramovay and Castro [10], and other authors [11], of high alcohol consumption in this age group. However, unlike the medical literature on the subject, there was a predominance of female adolescents in our sample - which is an intriguing fact- and may be indicative of behavioral changes in this age group, which deserves more accurate investigations in this regard.

Second, the victims of traffic accidents, drowning, and aspiration asphyxia were the ones that most revealed the influence of blood alcohol, followed by the victims of homicides. In the case of drowning deaths, $50 \%$ of the victims were drunk, which is a reasonable explanation for the accident.
In other words, the individual drinks, go swimming and ends up drowning.

Aspiration asphyxia was caused by direct suffocation due to food in the upper airways in adult individuals. In these cases, the blood alcohol level hindered normal swallowing, causing the food (usually barbecue meat) to obstruct the airway. Besides, similarly, fatal victims of falls (in accidents at work or not) were also drunk in $50 \%$ of cases.

In our sample, approximately $23.7 \%$ of the victims of suicide were under the influence of alcohol. A number that is slightly lower than that found in another study carried out in our country [13], perhaps because we did not include in this item the cases of exogenous intoxication (which we could not prove whether or not they were due to suicide).

In cases of traffic accidents in which there was an accident (by vehicle or train), $47.2 \%$ of the victims were drunk (average alcohol level of $1.9 \mathrm{mg} / \mathrm{dL}$ ). In other types of traffic accidents, in which the victim was the vehicle's driver, the positive blood alcohol level reached $48.7 \%$ (car drivers), and among the car passengers who died, $27.8 \%$. These data reveal 
the unmistakable influence of alcohol on the genesis of the automobile accident, influencing the driver's attitude when driving, and confirm the findings of other authors such as Enache, et al. [3]

However, a relevant question arises here in our study: to what extent did the fact that the victim was drunk contribute to the type of violent death that hit her? The answer is evident in drowning, falling, car accidents in which the driver was drunk or aspiring pieces of meat during a barbecue. But what about other types of violent death?

It is known that the action of alcohol in the body has two main phases. In the first, alcohol inhibits the inhibitory synapses in the Central Nervous System and releases impulses, often violent, which can also give rise to a fierce attitude on the aggressor. In the second phase, alcohol plays a frankly depressing role in the Central Nervous System, causing the individual to have reduced volition and attention, resist aggression, and drive vehicles - which leads to accidents, such as drowning, falls, and swallowing disorders. But what explains the relationship between alcohol and the firearm homicide victim?

In homicide cases, whether by firearms, knives, or blunt agents, the victims had blood alcohol levels above those established in $40.5 \%$ of the cases. In some types of homicides (e.g. by strangulation or drowning), it is clear that high blood alcohol levels have contributed to decreasing the victim's resistance. In others (e.g by firearm projectile and cutting agents), reaching $26.3 \%$ of the total cases, the explanation is not so simple. Perhaps further studies are needed to correlate the crime scene, the genesis of events, to find a satisfactory answer. The most plausible explanation is that the individual under the influence of alcohol is more frequently involved in fights and other forms of interpersonal violence, which may not be the only possible explanation.

Another interesting finding in our study deserves attention: the incidence of female adolescents who are drunk victims of violent death. The fact that women are less affected by the influence of alcohol in our sample reveals a cultural characteristic of Brazilian society. Traditionally, women drink minor (and have less resistance to the effects of alcohol) than men. However, as explained above, female adolescents enter this vicious circle of alcohol violence is a fact of our research that should draw attention and deserve more accurate studies.

\section{Final considerations}

The association between alcohol and violence has been known throughout the ages. Our study showed that the fact that the victims were drunk contributed significantly to the fatal outcome, not only in accidents but also in cases of homicide. In the case of accidents, blood alcohol levels were a direct contributing factor. In contrast, in other cases, their contribution was made indirectly, but no less important in the genesis of the crime.
Our study has some flaws, such as the fact that it comes from a retrospective analysis of the data, and there is no comparison with victims of natural deaths blood alcohol levels. However, the questions it raises (i.e., high blood alcohol levels among female adolescents; the relationship between homicides and blood alcohol levels) are essential for forensic purposes. Furthermore, despite the socio-cultural differences between the Brazilian population and other culturally distinct countries, it may favor future research on alcohol use and violence, which will undoubtedly be relevant in social terms.

\section{References}

1. Ministério da Saúde. Sistema de Informação sobre Mortalidade. 2010. http://www2.datasus.gov.br/DATASUS/index.php?area=040701

2. Lockemann U, Heinemann A, Wischhusen F, Ewerwahn J, Püschel K Frequently misinterpreted blood alcohol concentrations in (sudden) natural and unnatural death. Versicherungsmedizin. 1995; 47: 15-17. PubMed: https://pubmed.ncbi.nlm.nih.gov/7709500/

3. Enache A, Chatzinnikolaou F, Enache F, Enache B. The analysis of letha traffic accidents and risk factors. Legal Medicine. 2009; 11: S327-S330. PubMed: https://pubmed.ncbi.nlm.nih.gov/19254871/

4. Abel EL, Zeindenberg P. Age, Alcohol and violent death: a postmortem study. J Stud Alcohol. 1985; 46: 228-231.

PubMed: https://pubmed.ncbi.nlm.nih.gov/4010300/

5. Jena S, Mountany L, Muller A. A demographic study of homicidesuicide in the Pretoria region over a 5 year period. Journal of Forensic and Legal Medicine. 2009; 16: 261-265.

PubMed: https://pubmed.ncbi.nlm.nih.gov/19481707/

6. Skibin L, Bilban M, Balazic J. Harmful alcohol use of those who died a violent death-The extended region of Ljubljana 1995-1999. Forensic Sci Int 2005; 147: S49-52.

PubMed: https://pubmed.ncbi.nlm.nih.gov/15694729/

7. Fonseca AM, Galduroz JCF, Tondowski CS, Noto NA. Alcohol-related domestic violence: a household survey in Brazil. Rev Saúde Pública 2009; 43: 743-749.

PubMed: https://pubmed.ncbi.nlm.nih.gov/19722004/

8. Martín FM. La Violencia en la pareja. Rev Panam Salud Publica.1999; 5: 245-257.

9. Hall J, Goodall EA. Alleged drug facilitated sexual assault (DFSA) in Northern Ireland from 1999 to 2005 . A study of blood alcohol levels. J Forensic Legal Med. 2008; 15: 497-504.

PubMed: https://pubmed.ncbi.nIm.nih.gov/18926501/

10. Abramovay M, Castro GM. Drogas nas escolas. Brasília: UNESCO, 2005

11. Heninger M, Hanzlick R. Nonnatural Deaths of Adolescents and Teenagers Fulton County, Georgia, 1985-2004. Am J Forensic Med Pathol. 2008; 29: 208-213.

PubMed: https://pubmed.ncbi.nIm.nih.gov/18725773/

12. Carlini EA, Galduróz JC, Noto AR, Carlini CM, Oliveira, LG, et al. II Levantamento domiciliar sobre o uso de drogas psicotrópicas no Brasil: estudo envolvendo as 108 maiores cidades do país - 2005. São Paulo: Páginas \& Letras; 2007.

13. Ponce JC, Andreuccetti G, Jesus MGS, Leyton V, Muñoz DR. Álcoo em vítimas de suicídio em São Paulo. Rev Psiq Clín.2008; 35: 13-16.

14. Andreuccetti G, Cherpitel CJ, Carvalho HB, Leyton V, Miziara ID, et al Alcohol in combination with illicit drugs among fatal injuries in Sao Paulo, Brazil: An epidemiological study on the association between acute substance use and injury. Injury. 2018; 49: 2186-2192. PubMed: https://pubmed.ncbi.nlm.nih.gov/30270012/

15. Hanzlick R. Ethanol Concentration in Decomposing Bodies: Another Look, Less Concern. Am J Forensic Med Pathol. 2009; 30: 88-89. PubMed: https://pubmed.ncbi.nlm.nih.gov/19237865/ 